\title{
HISTAMINES AND FOODS: A REVIEW ON IMPORTANCE, DETECTION AND CONTROLLING IN FOODS
}

\author{
R. Mahmoudi ${ }^{*}$, K. Mardani ${ }^{2}$ \\ ${ }^{1}$ Department of Food Hygiene and Aquatics, Faculty of Veterinary Medicine, University of Tabriz, Tabriz ,Iran. \\ ${ }^{2}$ Department of Food Hygiene and Quality Control, Faculty of Veterinary Medicine, Urmia University, Urmia, \\ Iran \\ *Corresponding author: r.mahmodi@yahoo.com
}

\begin{abstract}
Biogenic amines are basic nitrogenous compounds that are generated in the course of microbial, vegetable, and animal metabolism. These compounds are found in varying concentrations in a wide range of food including fish, cheese, meat, wine, beer, vegetables, and chocolate. Although the biogenic amines play a number of important physiological functions in the human and animal bodies, its high level can have toxic effects on human and animal's organs. High amount of amines can be produced by bacteria during amino acids decarboxylation and have been identified as one of the important agent causing seafood intoxication. The most frequent food borne biogenic amine induced health issues is caused by histamine. Various analytical techniques have been used to determine the concentration of biogenic amines including chromatography, enzymatic methods and commercial kits based on immunoassay methods. Temperature is the main factor to control biogenic amine formation in food. A variety of techniques can be combined together to control the microbial growth and enzyme activity during processing and storage for better shelf life extension and food safety.
\end{abstract}

(Keywords: Biogenic amines, Food poisoning, Histamine)

\section{INTRODUCTION}

Biogenic Amines (BAs) are low molecular weight organic bases with biological activity that are formed in foods by either microbial decarboxylation of the corresponding amino acids or transamination of aldehydes and ketones by amino acid transaminases [1]. The most important BAs including histamine, tyramine, tryptamine, putrescine, and cadaverine are formed from free amino acids namely histidine, tyrosine, tryptophane, ornithine and lysine, respectively. Spermidine and spermine arise from putrescine [2]. Putrescine, cadaverine, spermidine, and spermine have an aliphatic structure; histamine and tryptamine have a heterocyclic structure and tyramine and phenylethylamine have an aromatic structure [3]. Free amino acids either occur in foods or may be liberated through proteolysis. In addition to the availability of precursors (amino acids), BAs accumulation in foods requires the presence of microorganisms with amino acid decarboxylases and favorable conditions for their growth and decarboxylation activity. The concentrations of biogenic amines in foods have been suggested as indices for bacterial contamination in food [2].

\section{Histamine}

Histamine is a naturally occurring biogenic amine. It can be found in foods such as fish, fish products, meat, cheese and fermented foods. The presence of histamine in these foods can indicate spoilage or poor manufacturing processes [4]. Histamine is identified by the Food and Drug Administration (FDA) as a major chemical hazard of seafood products [5]. Ingesting food with high levels of histamine $(5 \mathrm{mg} / \mathrm{g}$ ) can cause vomiting, diarrhoea, abdominal cramps, perspiration, flushing, headaches and burning sensations in the mouth $[4,5]$.

\section{Histamine and dairy products}

Cheese like other fermented food, usually contains high levels of BAs, because one of the biochemical processes which take place during cheese ripening is the degradation of proteins, leading to the accumulation of free amino acids. Because of the bacterial decarboxylases activity, some amino acids can be converted into amines [6].

The most important BAs from the food hygiene point of view are primary amines which include tyramine, histamine and cadaverine [6]. Such amines were recorded as most abundant BAs in cheese [7]. The production and levels of BAs in cheese depend on their free amino acids contents, bacterial load, $\mathrm{pH}$ and salt concentration as well as storage temperature [8], thus the amount of BAs in cheese may act as a useful indicator of the hygienic quality of the product. In other words, the existence of BAs in cheese is related to its spoilage [9].

Cheese is among the most commonly implicated foods associated with histamine poisoning and tyramine toxicity. Several cases of histamine poisoning have been reported in Netherland, United States, France and Swiss cheese containing more than $100 \mathrm{mg}$ histamine in $100 \mathrm{~g}$ cheese was involved in histamine poisoning outbreaks [10].

In a study by Ehsani et al. (2012, three types of Iranian cheese including Feta, Lighvan and Kope were investigated for histamine content as a biogenic amine by Ion-Exchange Chromatography. The study indicated significant differences in histamine contents 
among the examined cheeses, with the highest mean content of $42.6 \mathrm{mg} / 100 \mathrm{~g}$ for Kope cheese, and the lowest mean level of $4.99 \mathrm{mg} / 100 \mathrm{~g}$ in Feta cheese. In microbiological studies, Kope cheese samples had the highest total yeast $(24 \%)$ and bacterial contents $(36 \%)$. None of the isolates were found to be of major pathogenic importance [11].

\section{Histamine and fish products}

The scombroid fish, a certain type of fish can contain the amino acid histidine. Histidine can be converted into histamine by bacteria after fish being caught, and it can occur immediately if fish is not chilled properly after being caught. Since, histamine poisoning is a consequence of improper handling or storage of fish, therefore, the presence of histamine in foodstuffs, particularly in fish products can be used as an indicator for food hygiene [5].

Seafood may harbor a number of biological, chemical, and physical hazards, the most prevalent of which are biogenic amines (BAs) and biotoxins (chemical), pathogenic bacteria and viruses (biological), and metal inclusion (physical) [1].

Seafood is susceptible to contamination by BAsproducing microorganisms at different points of the food chain. Histamine poisoning occurs throughout the world and is perhaps the most common form of toxicity caused by the ingestion of fish. The consumption of high amount of BAs, above all histamine, can result in food-borne poisoning which is a worldwide problem Reporting several outbreaks of the histamine poisoning from many countries, it became one of the most prevalent forms of seafoodborne disease throughout the world. However, reliable statistics about its incidence do not exist because poisoning incidents are often unreported due to mild symptoms, lack of adequate reporting systems, or misdiagnoses by medical personnel of histamine poisoning as a food allergy $[12,13]$.

Recent recommendations for increasing fish consumption due to its health benefits by nutrition experts, histamine poisoning probably will play an important role in public health. Furthermore, the worldwide networking for catching, processing and distributing of fish products has made histamine poisoning as a global problem. To combat this problem, there are effective testing methods to quantify histamine levels. Therefore, control and prevention of histamine poisoning is possible [14, 15]. In Iran, canned tuna fish is extensively produced and frequently consumed by people. Therefore, the most of human histamine poisoning is associated with consuming canned fish containing high levels of histamine.

There are many reports on the amount of histamine in canned fish samples from Iran (Table 1), in a study by Kamkar et al. (2003) reported that histamine levels in Iranian canned tuna and sardine samples ranged from 10 to $178 \mathrm{mg} / \mathrm{kg}$ for canned tuna fish and 5 to $47 \mathrm{mg} / \mathrm{kg}$ for canned sardins samples [16]. The results of Rahimi et al. (2012) studied on histamine contents of canned tuna fish produced from 5 manufactures in Iran showed that the presence of histamine in $69.8 \%$ of canned tuna fish samples in concentration between 17 to $210 \mathrm{mg} / 100 \mathrm{~g}$ [4].

Another survey identified the Histamine content in canned tuna fish in Qazvin province from Iran by ELISA method. Histamine was detected in $29.37 \%$ canned tuna fish samples. The overall mean level of histamine was $8.59 \pm 14.24 \mathrm{ppm}$ and the concentration was between 2.51 and $74.56 \mathrm{ppm}$. The results of this study indicate that the most canned tuna fish produced in Qazvin province of Iran has histamine levels lower than the allowable limit suggested by FDA [17].

In a study by Hosseiny et al. (2007) the 88 samples of tuna fish cans were tested by ELISA method. The obtained results showed that 44.3 percent of them contained higher amount of histamine than the permitted limit (50 ppm). Also it became specified that the tuna fish cans produced in southern states, had higher amounts of histamine in comparison to the products of northern and central regions [18].

Table 1. Reports of histamine content in some food product from Iran in recently years.

\begin{tabular}{clll}
\hline Year & \multicolumn{1}{c}{ Products } & \multicolumn{1}{c}{ Survey method } & References \\
\hline 2003 & Fish (Iranian canned tuna and sardine) & ELISA & Kamkar et al. \\
2007 & Fish (tuna fish cans) & ELISA & Hosseiny et al. \\
2012 & Dairy (Feta, Lighvan and Kope cheese) & Ion-Exchange Chromatography & Ehsani et al. \\
2012 & Fish (canned tuna Fish) & ELISA & Rahimi et al. \\
\hline
\end{tabular}




\section{BAs detection methods}

Several analytical techniques including: Thin-layer chromatography (TLC), High-performance liquid chromatography (HPLC), Gas chromatography (GC), Capillary zone electrophoresis (CZE) and Ionexchange chromatography (IEC) have been employed to determine the amount of BAs in foodstuffs. HPLC method is widely used for detecting BAs concentration in food because of its sensitivity, reliability and reproducibility $[19,20]$.

The selectivity of enzymatic methods is superior. Flow injection has been used in combination with enzyme electrodes for easy automation [21]. Recently, there are many commercial kits based on selective antibodies for histamine detection [22].

The most rapid method for detecting histamine is based on flow injection analysis (FIA) and is capable of screening 60 sample extracts/hour. Enzymatic methods are attractive for their selectivity and flow injection has been used in combination with enzyme electrodes for easy automation. Many other commercial test kits are available, based on selective antibodies. Commercial test kits based on immunoassay methods for histamine analyses became popular because of their user friendliness and reduced time requirements compared to those of traditional analytical techniques [13].

\section{Controlling program}

The FDA has issued industry guidelines aiming at establishing procedures for the safe processing and importing of fish and fishery products based on the hazard analysis and critical control points (HACCP) approach [15]. According to the most recent HACCP guidelines for the control of histamine production, a core temperature of $4.4^{\circ} \mathrm{C}$ or less should be achieved and maintained throughout handling, processing, and distribution of potentially hazardous fish, also in this case the growth of spoilage bacteria (capable of producing histamine) inhibited [15]. It must be highlighted, however, that the time required lowering the internal temperature of fish after capture depends on a number of factors, including: (1) the harvest method, (2) the size of the fish, (3) the chilling method. Once, it is chilled the scombrotoxin-forming fish should be maintained as close as possible to the freezing point (or held frozen) until consumption [15]. At the processing plant, fish is gilled and gutted, then stored in ice until packed for air transport to the consumer country. Histidine decarboxylase activity could lead to a 10-fold increase in histamine during processing, air freight and marketing. The preventive measures for this step include controlling refrigeration temperature in the plant or performing proper icing during storage of raw material, in-process product as well as finished product [5]. During processing of fish (butchering, cleaning, brining, salting, smoking, drying, fermenting, pickling, mixing, stuffing, packing, labeling, and staging), it is recommended that processed fish must not exposed to ambient temperatures above $4.4{ }^{\circ} \mathrm{C}$ for more than $12 \mathrm{~h}$ cumulatively [15]. Given the heat-stable nature of histamine, the intended use of the product is not likely to affect the significance of this hazard. Recontamination of seafood with enzyme-forming bacteria in conjunction with temperature abuse may also allow for histamine formation following cooking. Thus, a conscientious sanitation program during seafood processing is of vital importance in order to avoiding recontamination [23]. Many recent studies proposed a new approach based on the employment of microorganisms or substances (additives, spices, disinfectants) able to inhibit histamine-forming bacteria. Mahmoudi (2014) studied the effect of different concentrations of Allium ascalonicum Essential Oil (EO) on the formation of histamine in the feta cheese during the ripening period. Data analysis demonstrated that the ripening time and different concentrations of EO were significantly affected histamine content in feta cheese [24]. Feta cheese sample containing the high level of EO had the lowest content of histamine at the end of the ripening period. Mah and Hwang (2009a) studied the effects of food additives on BAsproducing strains of Bacilluslicheniformis isolated from Myeolchi-jeot, with the greatest inhibitory effect being observed for glycine [25]. The same product (Myeolchi-jeot) was ripened with the addition of a starter culture of Staphylococcus xylosus, which was shown to be capable of degrading histamine and tyramine, while the use of spices, in particular garlic, also showed an inhibitory effect [26]. The development of post-harvest treatments for reducing histamine forming bacteria in fish upon harvest is an important intervention strategy to prevent histamine formation in fish and control scombroid poisoning. Phuvasate and $\mathrm{Su}$ (2010) investigated the efficacy of treatments with Electrolyzed Oxidizing water and Electrolyzed Oxidizing ice, containing 100 ppm chlorine [27]. According to these researchers, soaking of fish (salmon) in Electrolyzed Oxidizing' water reduced Enterobacterae rogenes and Morganella morganii by 1.3 and $2.2 \log \mathrm{CFU} / \mathrm{cm} 2$, respectively, while soaking yellowfin tuna in EO ice reduced the same microorganisms by 2.4 and $3.5 \log \mathrm{CFU} / \mathrm{cm} 2$, respectively. Moreover, emerging methods potentially applied as control measures include the addition of starter cultures that degrade histamine, the application of hydrostatic pressure, irradiation, and packaging [28].

\section{CONCLUSION}

Histamine poisoning occurs throughout the world and is perhaps the most common form of toxicity caused by the ingestion of fish. Reporting several outbreaks of the histamine poisoning from many countries, it became one of the most prevalent forms of seafoodborne disease throughout the world. High levels of BAs can be prevented through the using good quality 
raw material, application of good hygiene practices and proper temperatures during handling, delivery and storage. Although BAs formation is the result of bacterial growth, the presence of these undesirable compounds, especially histamine, is not always noticed by consumers.

The combination of the various preservative factors (hurdle system) in influencing the microbial stability, the organoleptic and nutritional quality of foods needs more investigation. Thus, the application of appropriate control measures is fundamental for assuring seafood safety and such a responsibility is shared among the seafood catchers, processors, distributors, retailers, and merchants.

\section{ACKNOWLEDGEMENT}

This work was financially supported by University of Tabriz, Tabriz, Iran.

\section{CONFLICTS OF INTEREST}

The authors declare that there are no conflicts of interest.

\section{REFERENCES}

1. Zhai H., Yang X., Li L., Xia G., Cen J., Huang H. and Hao S. 2012. Biogenic amines in commercial fish and fish products sold in southern china. Food Control 25:303-308.

2. Zarei M., Najafzadeh H., Enayati A. and Pashmforoush M. 2011. Biogenic amines content of canned tuna fish marketed in Iran. AmericanEurasian Journal Toxicology Scienec. 3: 190-193.

3. Mohamed R., Livia S.S., Hassan S., Soher E.S. and Ahmed-Adel E.B. 2009.Changesinfreeamino acids and biogenic amines of Egypt- ian saltedfermented fish (Feseekh) during ripening and storage. Food Chemistry. 115: 635-638.

4. Rahimi E., Nayebpour F. and Alian F. 2012. Determination of histamine in canned tuna fish using ELISA method. American Eurasian Journal Toxicology Science. 4(2):64-66.

5. Food and Drug Administration. 2001. Scombrotoxin (histamine) formation. In: Fish and fisheries products hazards and controls guidance. Center for Food Safety and applied Nutrition, Office of Seafood, Food and Drug and Administration, Washington, DC, pp 83-102.

6. Marino M.M., Maifreni S.M. and Rondinini G. 2000. The capacity of Enterobacteriaceae species to produce biogenic amines in cheese. Letter Applied Microbiology. 31:169-173.

7. Bonetta S.E., Carraro J.D., Coisson F. and Arlorio M. 2008. Detection of biogenic amine amines producer bacteria in atypical Italian goat cheese. Journal food Protection. 71 (1): 205-209.

8. Rodriguez S.N., Nogues Sagues M.T.V., Mesa A.J.T. and Carou M.C.V. 2002. Influence of starter and non starter on the formation of biogenic amine in goat-cheese during ripening. Journal Dairy Science. 85 (10): 2471-2478.

9. Sarikadi L. 2004. Histamine in food. In: Biology and medical aspect. Spring-Medicine Publishing Budapest, Hungary.

10. Stratton J. E., Hutkins, R.W. and Taylor S. L. 1991. Biogenic amines in cheese and other fermented foods - a review. Journal of Food Protection 54: 460-470.

11. Ehsani, A., Mahmoudi, R., Khodayari, M. and Zare, P. 2012. Histamine Levels in 3 Types of Iranian Cheese by Ion-Exchange Chromatography. Walailak Journal Scienec Technolgy. 9(3): 281-285.

12. Food and Agriculture Organization. 2004. Application of risk assessment In the fish industry. FAO Fisheries Technical Paper 442.Rome: Corporate Document Repository, Fisheries and Aquaculture Department.

13. Visciano, P., Schirone, M., Tofalo, R. and Suzzi, G. 2012. Biogenic amines in raw and processed seafood. Frontiers in microbiology, 3: 1-10.

14. Bulushi, I.A., Poole, S., Deeth, H.C. and Dykes, G.A. 2009. Biogenic amines in fish: roles in intoxication, spoilage, and nitrosamine formation e a review. Critical Review Food Science Nutrition. 49:369-377.

15. Food and Drug Administration. 2011. Fish and Fishery Products Hazards and Controls Guidance, 4th Edn. Washington, DC: Department of Health and Human Services, Food and Drug Administration, Center for Food Safety and Applied Nutrition.

16. Kamkar, A., Hosseini, H. and Abuhossein, G. 2003. A study of histamine contents of canned tuna and products sardine of Iran. Pajouhesh Sazandegi. 60:44-50.

17. Mahmoudi, R. and Norian R. 2014. Occurrence of histamine in canned tuna fish from Iran. Journal of Consumer Protection and Food Safety. 9 (1):133-136.

18. Hosseini, H., Keshavarz, S.A., Pirali, P., Khaksar, R., Abasi, M. and Fekri, M. 2007. Study of histamine content in canned tuna fish produced in Iran by ELISA method. International Journal Food Science Technology. 4(2):78-84.

19. Onal, A. 2007. A review: current analytical methods for the determination of biogenic amines in food. Food Chemistry.103: 1475-1486.

20. Csomos, E. and Simon-Sarkadi, L. 2002. Characterisation of tokaj wines based on free amino acids and biogenic amines using Ion exchange chromatography. Chromatography. 56: $185-188$

21. Watanabe, S., Matsuo, K., Suzuki, Y., Tachibana M., Tani K. and Koizumi, H. 2007. Determination of histamine in fish sauce by photometric flow injection analysis with immobilized histamine oxidase reactor. Bunseki Kagaku 56: 1033-1036. 
22. Kose, S., Koral S., Kaklikkaya, N., Buruk, C.K., Tufan, B. and Aydin, F. 2009. Investigating suitability of commercial histamine test kits for monitoring histamine in traditional fish products. Presentedat IFT Conference, Aquatic Food Products Division, 5-10 June 2009, Anaheim, CA.

23. Arena, M.E., Landete, J.M., Manca, de Nadra, M.C., Pardo, I. and Ferrer, S. 2008. Factors affecting the production of putrescine from agmatine by Lactobacillus hilgardii X1B isolated from wine. Journal Applied Microbiology. 105:158-165.

24. Mahmoudi, R. 2014. Effects of Allium ascalonicum essential oil on histamine formation in feta cheese. Academia Journal of Food Research. 2(1): 001-006.
25. Mah, J.H. and Hwang, H.J. 2009a. Effects of food additives on biogenic amine formation in MyeolchiJeot, a salted and fermented anchovy (Engraulisjaponicus). Food Chemistry. 114: 168173.

26. Mah, J.H. Hwang, H.J. 2009b. Inhibition of biogenic amine formation in a salted and fermented anchovyby Staphylococcusxylosus as a protectiveculture. Food Control. 20: 796-801.

27. Phuvasate, S., Su, Y.C. 2010. Effects of electrolyzed oxidizing water and ice treatments on reducing histamine-producing bacteria on fish skin and food con tact surface. FoodControl. 21: 286-291.

28. Naila, A., Flint, S., Fletcher, G., Bremer, P. and Meerdink, G. 2010. Control of biogenic amines in food-existing and emerging approaches. Journal Food Science. 75: 139-150. 